\title{
CATEGORÍAS PERCEPTIVAS Y CONCEPTOS
}

\author{
JUAN VÁZQUEZ \\ https://orcid.org/0000-0001-7517-7554 \\ Universidade de Santiago de Compostela \\ bttp://dx.doi.org/10.15304/ag.39.2.6666
}

\section{Resumen}

El estudio del desarrollo cognitivo ha estado y todavía sigue estando enfrentado a dos problemas fundamentales, vinculados entre sí, y para los que no se ha encontrado una respuesta satisfactoria. El primero de estos problemas se refiere a una distinción terminológica y los correspondientes contenidos semánticos - qué rasgos o características permiten distinguir a los perceptos (esquemas perceptivos o categorías perceptivas) de los conceptos propiamente dichos. El segundo problema, que depende de esa distinción, consiste en determinar de qué modo y en qué momento del desarrollo cognitivo se produce el paso o transformación de las categorías perceptivas en conceptos. Este trabajo proporciona una respuesta clara y precisa a esas dos cuestiones.

Palabras clave: Desarrollo cognitivo, percepción, información sensorial, información categorial, categorías perceptivas, lenguaje, representación simbólica, conceptos.

\begin{abstract}
The study of cognitive development has been, and still is, faced with two fundamental problems. They are connected, and no satisfactory answer has been found to either. The first problem concerns a terminological distinction and the corresponding semantic contents - it is important to be clear about which characteristics make it possible to distinguish percepts (or perceptual schemes or perceptual categories) from concepts proper. The second problem, which depends on such distinction, consists in determining when and how, in cognitive development, the turn from perceptual categories into concepts occurs. This paper provides a clear and precise answer to both questions.

Keywords: Cognitive development, perception, sensory information, categorial information, perceptual categories, language, symbolic representation, concepts.
\end{abstract}




\section{Aclaraciones terminológicas}

En La arquitectura cognitiva de la percepción (Vázquez, 2013, 2014), siguiendo a Gregory Murphy (Murphy, 2004) y Paul Thagard (Thagard, 2005), entre otros, había hecho uso de las nociones de categoría perceptiva y concepto en un sentido que no es el habitual tanto en el ámbito de la Filosofía como en el de la Psicología Cognitiva. En el ámbito de la Filosofía el término categoría se ha tendido a utilizar como referido a géneros supremos, tales como substancia, cantidad y cualidad, independientemente de que esos géneros supremos se los entienda, en un sentido realista, como es el caso de Aristóteles, o bien en un sentido puramente formal, como acontece en Kant. Por el contrario, en el ámbito de la Psicología Cognitiva lo habitual es utilizar los términos categoría y concepto como sinónimos y en un sentido muy próximo al uso que se hace del término concepto en el ámbito de la Filosofía. Así, de acuerdo con la clasificación elaborada por Eleanor Rosch, (Rosch, 1976) tendríamos, dependiendo del mayor o menor grado de abstracción o generalidad, los tres tipos siguientes de categorías: las de nivel básico (perro, gato, silla, árbol, etc.), las de nivel superordinado (animal, vegetal, ser vivo, etc.) y las de nivel subordinado (caniche, petirrojo, siamés, etc.)

A diferencia de esos distintos tipos de usos, en La arquitectura cognitiva de la percepción he utilizado los términos categoría y concepto en un sentido próximo al que es habitual en el ámbito de la Psicología Cognitiva, pero distinguiendo claramente entre categorías perceptivas y conceptos. Se entendía por categorías perceptivas al resultado de agrupar la información sensorial, derivada del procesamiento de los estímulos, en clases significativas mediante la búsqueda de rasgos compartidos. Así tendríamos los distintos tipos de categorías o clases de cosas en el mundo como, por ejemplo, la clase de los perros, la de los gatos, la de los pájaros y toda esa amplísima variedad de tipos de entidades a las que acostumbrarnos a referirnos mediante el uso de los nombres y que nuestro sistema perceptivo logra identificar de una manera asombrosamente eficaz. Y entendemos por conceptos la representación mental de esa misma clase de entidades o tipos de cosas en el mundo. En palabras de Paul Thagard and Ethan Toombs: "Concepts are mental representations that usually correspond to particular words and refer to classes of things in the world. For example, the concept [DOG] corresponds to the word $d o g$ and refers to the class of dogs in the world. Categorization is the process of dividing the world into categories, and usually involves constructing concepts that provide mental representations of those categories" (Thagard, P. and E. Toombs, 2005, p. 244). 
En este texto voy a seguir haciendo uso de las expresiones "categoría perceptiva" y "concepto" en ese mismo sentido, pero con el propósito ultimo de destacar las profundas diferencias existentes entre la identificación perceptual de las categorías o tipos de cosas en el mundo y la representación mental que nos hacemos de ellas a través de los conceptos. También es un propósito de este trabajo indicar de qué modo y en qué momento del desarrollo cognitivo se produce el paso de las categorías perceptivas a los conceptos.

\section{El desarrollo cognitivo}

De acuerdo con la hipótesis esbozada por Vladimir M. Sloutsky en "From Perceptual Categories to Concepts: What Develops?" (Sloutsky, 2010), en el estudio del desarrollo cognitivo debemos tomar en consideración tres elementos fundamentales: a) la estructura del input: el distinto tipo de información estimulativa que subyace a los diversos tipos de categorías perceptivas, b) los sistemas neuronales de aprendizaje implicados en su procesamiento y, por último, c) el curso de maduración de cada uno de esos sistemas neuronales.

Las investigaciones empíricas muestran que con anterioridad a la aparición del lenguaje los niños ya disponen de al menos dos tipos distintos de categorías perceptivas, un primer tipo de categorías de carácter global, en general vinculadas con la percepción del movimiento y la espacialidad, entre las que se encontrarían, entre algunas otras, las categorías de animado e inanimado, continente y contenido, (Mandler, 2004) y un segundo tipo que estaría constituido, de acuerdo con la clasificación categorial de Eleanor Rosch (Eleanor Rosch et al. 1976), por las categorías de "nivel básico", las categorías de los perros, gatos, pájaros, mesas, árboles, etc. Este segundo tipo de categorías de nivel básico se caracterizan por su alto grado de informatividad (informativeness) y distintividad (distinctiveness). Es decir, por estar constituidas por una estimulación densa, con un gran número de caracteres o propiedades interrelacionadas, relevantes en la determinación de la categoría (forma, color, tamaño, estructura, etc.). y significativamente distintas de los rasgos o propiedades compartidos por los miembros de otras categorías, lo que proporciona a los miembros de una misma categoría un alto grado de similitud, lo que, evidentemente, desde un punto de vista cognitivo, favorece la constitución de este tipo de categorías que no sólo los bebés pre-lingüísticos pueden aprender de una manera implícita, no 
consciente y automática, sino también un número considerable de especies animales (Smith et al., 2008; Zentall et al., 2008). Que estos dos tipos de categorías perceptivas sean las primeras en ser adquiridas por los niños tiene también una fácil explicación desde un punto de vista neurofisiológico, ya que se trata, en su origen, de categorías unimodales, a las que se puede acceder mediante el uso de uno solo de los sentidos. Y, en ambos casos, en su procesamiento, al nivel de la corteza cerebral, sólo estarían implicadas, en un primer momento, las áreas sensoriales primarias y asociativas de cada sentido, las primeras en adquirir una pronta maduración.

El paso siguiente en el proceso del desarrollo cognitivo radica en la capacidad para integrar la información procedente de las distintas modalidades sensoriales. Inicialmente los sistemas sensoriales están separados unos de otros y sólo con la lenta maduración de las neuronas multisensoriales y el aprendizaje se produce la integración intermodal de la información sensorial (Wallace, 2004). Un proceso que está en la base tanto de la aparición del lenguaje, que implica la vinculación de la información procedente del sentido de la vista con la del sentido del oído, como la de adscribir a una misma categoría la información proveniente de sentidos distintos: los perros ladran, los pájaros cantan y los humanos hablan.

El desarrollo de las áreas intermodales, en donde toma lugar el procesamiento de la información procedente de los diversos sentidos, proporciona la base neurológica necesaria para el aprendizaje del lenguaje. Y, tal como muestran las investigaciones empíricas, los nombres que se refieren a las categorías de nivel básico del entorno del niño se encuentran entre las 100 primeras expresiones por él utilizadas con más frecuencia (Nelson, 1973). En definitiva, que el aprendizaje del lenguaje se inicia con la lexicalización de las categorías de nivel básico, de las que ya dispone el niño pre-lingüístico.

La lexicalización abre la puerta a múltiples posibilidades: la de adquirir conocimiento de propiedades inobservables acerca de los miembros de las categorías como, por ejemplo, que los perros o los gatos tienen pulmones y corazón; la de hacer uso de una combinación de información lingüística y perceptual en la adquisición de nuevas distinciones ontológicas; la de acceder a categorías menos densas, entre las que se encontrarían, por ejemplo, las categorías de orden superordinado, etc. etc.

A diferencia de lo que acontece con las categorías de nivel básico, las categorías de nivel superordinado implican un proceso de atención selectiva, la capacidad de poder tomar en consideración tan sólo algunas de las propiedades que definen a la categoría, pasando por alto todas las demás. De las muchas propiedades que permiten identificar a un perro, un caballo 
o un pájaro como tales, sólo algunas de esas propiedades son las que deben ser tenidas en cuenta a la hora de incluirlos en la categoría menos densa de animal, en este caso que perros, caballos y pájaros son seres orgánicos que viven, sienten y se mueven por propio impulso. En ese proceso de selección van a estar implicadas no sólo las áreas sensoriales primarias y asociativas de cada uno de los sentidos y las multisensoriales sino también la corteza prefrontal dorso-lateral, de la que dependen, entre otras muchas funciones ejecutivas, la fijación de la atención y la toma de decisiones. Y hoy sabemos que la corteza prefrontal dorso-lateral experimenta una maduración relativamente tardía (Davidson, Amso, Anderson, y Diamond, 2006). De hecho, las categorías de orden superordinado, entre las que se encontraría la categoría de animal, no son adquiridas por los niños hasta una edad bastante tardía, entre los 4 y los 6 años (Markman, 1989).

En todo este largo proceso del desarrollo cognitivo lo que merece ser destacado como más importante y trascendental, en relación con la distinción entre categorías perceptivas y conceptos, es que con la lexicalización, como luego veremos con más detalle, el pensamiento, los contenidos categoriales de la percepción, toman cuerpo en la palabra, se independizan de la información sensorial en la que se configuran a nivel perceptivo y se transforman en pensamiento abstracto y conceptual.

El proceso de categorización a nivel perceptivo significa una simplificación del medio, una reducción de la carga de la memoria, un modo de almacenar y recuperar información que va más allá del conocimiento específico de los entes singulares. En definitiva, el sistema de categorización nos proporciona una mayor información con un menor esfuerzo cognitivo. A través del proceso de categorización los entes cognitivos taxonomizamos el mundo, agrupamos la información sensorial en objetos, eventos, propiedades, relaciones y demás clases significativas, lo que es fundamental para la supervivencia, ya que nos permite tratar eficazmente a los miembros de la misma categoría o clase de una manera similar. Pero esa habilidad, en mayor o menor grado, la poseen también el resto de los seres vivos. Para poder sobrevivir un perro, un gato o cualquier otro animal, han de ser capaces de distinguir lo que para cada uno de ellos es un alimento adecuado de lo que no lo es, cuáles son sus depredadores potenciales o sus posibles presas. Y, si desean reproducirse, han de poder identificar a los miembros de su misma especie y distinguir a los machos de las hembras. En el caso concreto de los seres humanos el proceso de categorización se inicia a edades muy tempranas, de tal modo que, con anterioridad a la aparición del lenguaje, al final del primer año de vida, el niño ya posee un gran número de categorías per- 
ceptivas, ya vive en un mundo taxonomizado, más pobre, evidentemente, que el de un sujeto adulto, pero no esencialmente distinto ${ }^{1}$.

Con la aparición del lenguaje algunas de esas categorías experimentan un proceso de lexicalización, en primer lugar las categorías de nivel básico y, luego, a medida que prosigue el desarrollo, el resto de categorías de distinto nivel de generalidad (Davidson, Amso, Anderson and Diamond, 2006). El proceso de categorización es flexible, abierto a nuevas categorizaciones y a la modificación y enriquecimiento de las ya existentes, adaptándolas a las nuevas experiencias; de tal modo que en la edad adulta los sujetos humanos somos capaces de operar con decenas o cientos de miles de categorías. Esto significa que nuestro acceso perceptivo al mundo no lo es simplemente a un mundo de puras sensaciones, sino a un mundo categorizado en el que la información sensorial se nos hace presente configurando una determinada información categorial. Es más, la misma información categorial puede configurarse en informaciones sensoriales disponibles distintas y, a la inversa, distintas informaciones categoriales pueden configurarse en la misma información sensorial disponible. Todo depende de la dimensión de la realidad a la que en cada situación prestemos atención. Podemos identificar, pongamos por caso, un perro, un gato o un pájaro como tales viéndolos desde perspectivas distintas, a distancias también distintas y en cada una de las múltiples posiciones que pueden y suelen adoptar esos animales en su vida diaria, y esa identificación puede llevarse a cabo no sólo a través del sentido de la vista sino también a través del sentido del oído, del olfato o del tacto. La información sensorial será en cada caso distinta, pero la identificación categorial del perro como perro, del gato como gato y del pájaro como pájaro, es en todos los casos la misma. A través de los distintos sentidos nos abrimos al mismo mundo categorial, por más que esa infor-

1 "The ability to learn perceptual categories from relatively dense input has been demonstrated in nonhuman animals as well as in 3- and 4- month-old human infants (Coook \& Smith, 2006; Quinn et al., 1993; Smith et al., 2008; Zentall et al., 2008). Although some of these perceptual categories (e.g., cats, dogs, or food) will undergo lexicalization, others (e.g., some categories of speech sounds) will not". (Sloutsky, Vladimir M. (2010): "From Perceptual Categories to Concepts: What Develops?", Cognitive Science, 34 (2010), p. 1278).

"It is widely believed that children come into the process of vocabulary learning with a large set of unlabeled concepts. These early concepts may reflect the correlational structure in the environment of the young child, as suggested by Rosch et al. (1978). For example, a child may form a concept of dog around the correlated properties of four legs, tail, wagging, slobbering, and so forth. The subsequent learning of a word's meaning should be relatively easy to the extent that one can map that word onto one of these existing concepts" (Goldstone, R. L, \& Kersten, A., 2003, p. 613). 
mación categorial se constituya en una información sensorial distinta y, a la inversa, aquello que en un momento es identificado como un perro, en otro momento distinto puede ser identificado simplemente como un animal o un ser vivo, sin que por ello tenga que haber cambiado la información sensorial disponible sobre la que se han configurado esos distintos tipos de identificaciones categoriales. Y, lo que es más importante, a nivel consciente, la información sensorial no es previa a la categorial, sino que esa información sensorial se nos hace presente en los procesos de percepción configurando las correspondientes informaciones categoriales. No veo primero la forma y el color del perro o las formas y los colores del gato o del pájaro y, luego, identifico a esos animales como tales, sino que veo directamente en esas formas y esos colores las formas y los colores del perro, el gato o el pájaro. Y lo mismo sucede en relación con los demás sentidos y distintos tipos de categorías perceptivas. No oigo primero los sonidos que producen los perros al ladrar, los gatos al maullar y los pájaros al cantar y, luego, interpreto esos sonidos como el ladrido de un perro, el maullido de un gato o el canto de un pájaro, sino que esos sonidos son oídos directamente como ladridos, maullidos o cantos de pájaros. La información sensorial y la categorial están como envueltas la una en la otra y, aunque es la información categorial la que se configura en la sensorial, lo cierto es que la propia información sensorial es matizada en su ser perceptivo por la información categorial en ella configurada. "In particular, not only does the identification of features influence the categorization of and object, but also the categorization of and object influences the interpretation of features" (Goldstone, R. L. and Kersten, A., 2003, p. 611). Porque veo en la figura 1 del triángulo de Kanizsa un triángulo blanco que en realidad no existe, percibo la superficie de ese triángulo como más brillante que la de su entorno. Una diferencia de matiz igualmente inexistente en el mundo real. Y porque veo los dos rectángulos blancos horizontales de la ilusión de Ponzo (Figura 2) en el contexto de las vías del tren, hace que percibamos el rectángulo más alejado como mayor cuando de hecho los dos rectángulos tienen el mismo tamaño. En definitiva, que el ser categorial de los entes del mundo se configura en todas y cada una de sus manifestaciones sensoriales, por más que algunas de esas manifestaciones sensoriales sean específicas de cada sentido. 

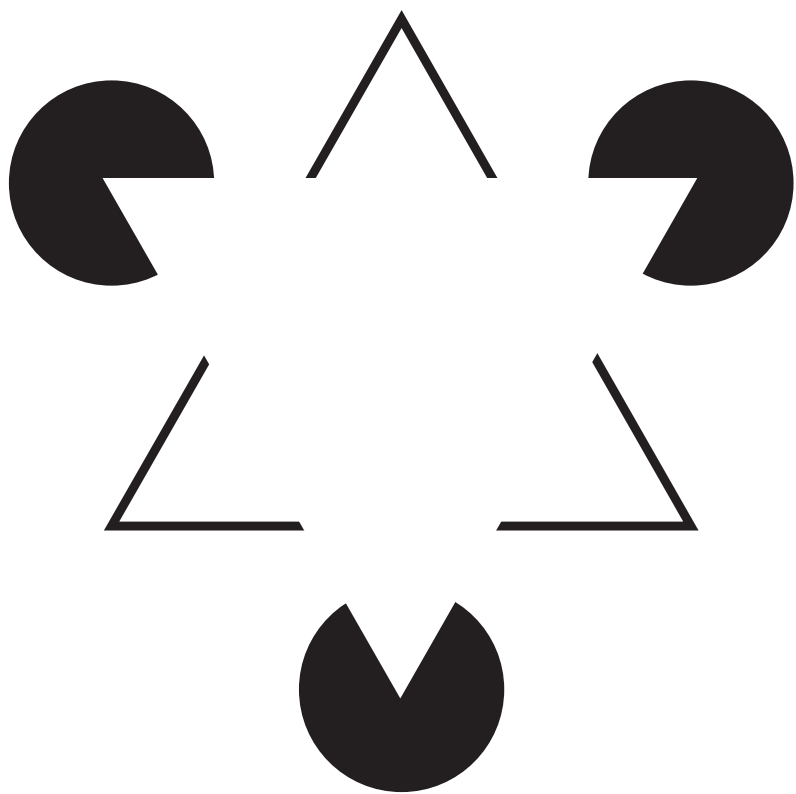

Figura 1. Triángulo de Kanizsa

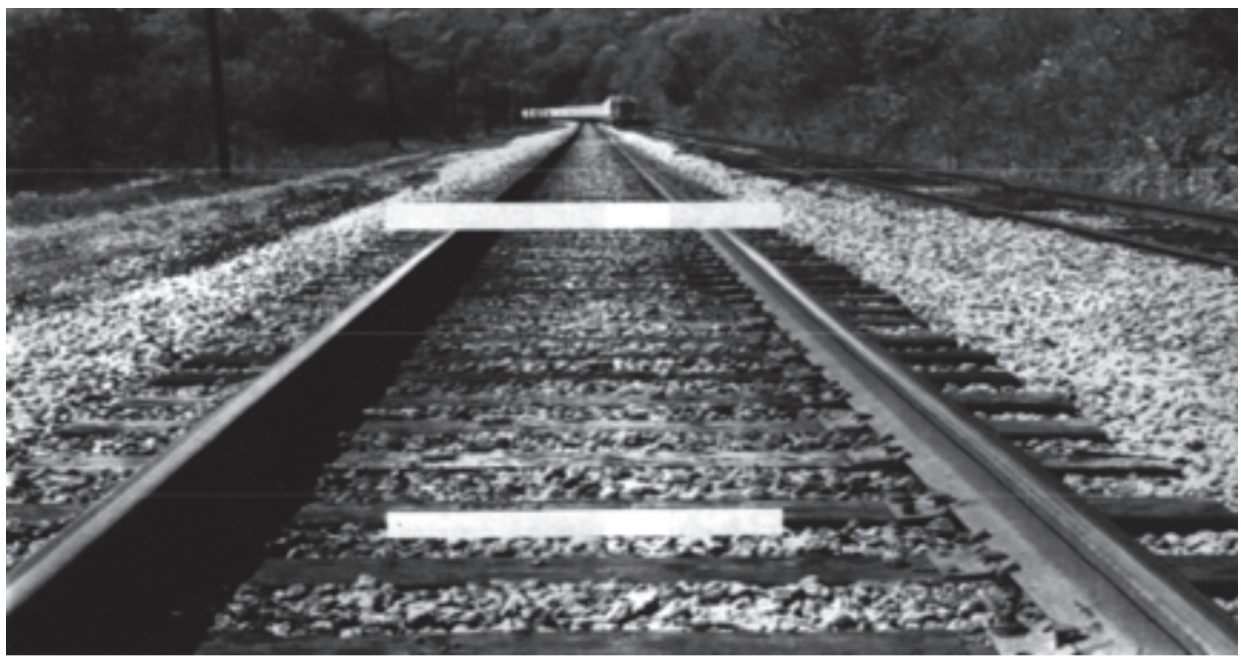

Figura 2. Ilusión de Ponzo

Evidentemente, para que yo o cualquier otro sujeto percibamos configurada en la información sensorial un determinado tipo de entidad, propiedad o relación, necesitamos disponer previamente de las categorías perceptivas 
correspondientes. Pero en los sujetos adultos, ya dotados de un sistema de categorización o taxonomización del mundo, la percepción proporciona a dichos sujetos dos tipos distintos de contenidos informativos, el sensorial y el categorial. Con la particularidad de que de esos dos tipos de contenidos informativos el relevante es el categorial, porque es la información categorial la que nos permite identificar los distintos tipos de entidades y adoptar una conducta coherente con relación a ellas. Un sujeto incapaz de percibir en la información sensorial la configuración de la información categorial correspondiente a esa información sensorial, sería un sujeto agnósico. Podemos percibir todas las propiedades sensoriales que caracterizan a un determinado tipo de entidad, pero si seguimos sin saber de qué entidad se trata, si somos incapaces de percibir configurada en esa información sensorial ninguna información categorial es, desde el punto de vista de nuestra interacción con el medio, peor que si fuéramos ciegos, sordo o mudos.

La tendencia a categorizar es innata en los seres humanos y también en los animales y el hecho de la categorización evidente. Una cuestión distinta es proporcionar una explicación satisfactoria de ese proceso, de cómo, cuándo y dónde se almacena la información relativa a los distintos tipos de categorías.

\section{De las categorías perceptivas a los conceptos}

Como ya se ha indicado anteriormente, con anterioridad a la aparición del lenguaje, el niño pre-lingüístico ya dispone de un gran número de categorías perceptivas de carácter global y de nivel básico, las relativas a su entorno más habitual. ¿Dispone el niño pre-lingüístico también de conceptos? Algunos psicólogos cognitivos, como puede ser el caso de Jean M. Mandler (Mandler, 2004), dirían que sí. Sin embargo, antes de contestar a esa pregunta, quisiera hacer algunas indicaciones de lo que acontece a nivel de los sujetos adultos en relación con la activación de los contenidos mentales, ya que de lo que sucede a nivel de los sujetos adultos vamos a poder inferir que acontece en la mente del niño pre-lingüístico.

En primer lugar deseo llamar la atención, tanto en relación con las categorías perceptivas como con los conceptos, que una cosa son las categorías perceptivas y los conceptos y otra muy distinta el soporte material en el que toman cuerpo. A nivel de las categorías perceptivas una cosa son las sensaciones en las que se configuran las categorías perceptivas y otra muy distinta las categorías en ellas configuradas. Como ya se ha mostrado ante- 
riormente, estímulos distintos pueden dar lugar a una misma identificación categorial y, a la inversa, unos mismos estímulos disponibles pueden servir de base a configuraciones categoriales distintas. A nivel del lenguaje y en relación con los conceptos acontece algo similar. Una cosa son los conceptos y otra muy distinta los signos orales o escritos en los que toman cuerpo. Unos mismos conceptos, pongamos por caso, los conceptos de perro o de gato, pueden hacérsenos presentes, respectivamente, a través de la palabra "perro" o de la palabra "gato", en su forma oral o escrita, o también a través de las expresiones correspondientes de otras lenguas, por ejemplo a través de las expresiones inglesas "dog" y "cat" o de las francesas "chien" y "chat". En todos estos casos la estimulación sensorial en la que toman cuerpo los conceptos de perro, por una parte, y la de gato, por la otra, será distinta, sin que esa diversidad de estimulación afecte a los respectivos contenidos conceptuales como tales.

Si bien es verdad, como acaba de indicarse, que tanto a nivel de la percepción como a nivel del lenguaje una cosa son los contenidos categoriales de la percepción o los contenidos conceptuales vinculados al lenguaje y otra muy distinta la estimulación sensorial en la que se configuran los primeros y toman cuerpo en la palabra los segundos, lo cierto es que incluso como sujetos adultos sólo accedemos conscientemente a esos dos tipos de contenidos a través de la estimulación sensorial en la que se configuran en el primer caso y de la palabra en la que toman cuerpo en el segundo. En ausencia de la información sensorial, a nivel perceptivo, y de la palabra, a nivel lingüístico, o de imágenes, nuestra mente está en blanco; bien entendido que las imágenes que, en determinadas ocasiones, pueden acompañar a los contenidos conceptuales, no son un constitutivo esencial de esos contenidos. Las imágenes, al igual que las impresiones sensoriales y a diferencia de los conceptos, pertenecen a la experiencia privada del sujeto. Aunque distintos de su soporte material, los seres humanos no tenemos acceso consciente a los contenidos categoriales de la percepción o a los conceptuales del lenguaje fuera de la información sensorial en la que se configuran los primeros y de la palabra en la que toman cuerpo los segundos. Si uno cualquiera de nosotros desea activar en su mente algo así como las ideas de perro o de gato sólo podrá hacerlo o bien identificando perceptivamente a uno cualquiera de esos animales o bien utilizando las expresiones léxicas correspondientes. En ausencia de ese soporte material en el que se configuran o toman cuerpo los pensamientos nuestra mente consciente está en blanco. Como dice y trata de demostrar Merleau-Ponty en Phénoménologie de la perception, "La pensé n'est rien d' «interieur», elle n'existe pas 
hors du monde et hors des mots" (Merleau-Ponty, 1945, p. 213). Si esto es así, como realmente creo que es, entonces los niños pre-lingüísticos, puesto que no disponen de lenguaje, sólo dispondrán de categorías perceptivas, o de imágenes reproductivas, más o menos precisas, de sus experiencias perceptivas, pero no de la representación simbólica de esas categorías, los conceptos. Por otra parte, posiblemente los niños pre-lingüísticos sólo tengan acceso a aquellas categorías perceptivas que están constituidas por una estimulación densa y que pueden ser adquiridas de una manera implícita, sin supervisión, como acontece con las categorías de nivel básico y también con algunas categorías de tipo global. En consecuencia, carece de sentido atribuir contenidos conceptuales a los niños pre-lingüísticos. Los conceptos sólo adquieren carta de naturaleza con el lenguaje, con su expresión simbólica en la palabra y sólo una vez que la palabra adquiere su carácter referencial y no es utilizada por el niño como si se tratara de una propiedad más de las cosas percibidas.

Con el proceso de lexicalización, las categorías perceptivas se independizan de la información sensorial en la que se configuran a nivel perceptivo, toman cuerpo en la palabra y se transforman en conceptos, dando lugar a la representación simbólica del conocimiento ${ }^{2}$, en un primer momento mediante el procedimiento de proporcionar expresión simbólica a los contenidos categoriales de la percepción y, luego, una vez que el pensamiento se auto-objetiva en la palabra y se independiza de la información sensorial, ya es posible acceder, con la ayuda del lenguaje, al enriquecimiento de las categorías ya adquiridas con propiedades no vinculadas directamente con la percepción, y al aprendizaje y constitución de nuevos pensamientos, cada vez más abstractos y alejados de la experiencia sensible. Es sólo a través de la constitución del pensamiento en la palabra, como resultan posibles la adscripción a las categorías de propiedades no directamente perceptibles, el pensamiento abstracto, la generación de imágenes creativas, las inferencias complejas y, en general, el conocimiento científico.

De acuerdo con lo dicho hasta aquí, debemos suponer que una gran cantidad de animales que no disponen de expresión simbólica, sí que pueden disponer de ciertas categorías perceptivas de nivel básico, similares a las categorías perceptivas de los niños pre-lingüísticos, de lo que no podrán disponer esos animales, en la medida en la que no dispongan de expresión simbólica, es de conceptos. A nivel perceptivo, los contenidos categoriales

2 "Therefore, lexicalization is a critical step in the transition from perceptual grouping to concepts” (Sloutsky, Vladimir M., 2010, p. 1279). 
de la percepción, tanto en el momento de irse constituyendo en la primera infancia como, luego, en la edad adulta, mantienen siempre, como vamos a ver a continuación, una serie de rasgos que permiten distinguirlos claramente de su representación conceptual, a nivel simbólico. De señalar esas diferencias entre la información categorial, vinculada a la información sensorial, y los conceptos, que toman cuerpo en la palabra es, precisamente, de lo que voy a ocuparme a continuación.

\section{Categorías perceptivas y conceptos: afinidades y diferencias}

En el cuadro que sigue y a modo de presentación, se indican los rasgos o propiedades más relevantes que permiten distinguir a las categorías perceptivas de los conceptos y es del análisis de esos rasgos de lo que ahora voy a ocuparme:

\begin{tabular}{|l|l|}
\hline Categorías perceptivas & Conceptos \\
\hline Presentacionalidad & Representacionalidad \\
\hline Horizontalidad & No horizontalidad \\
\hline Determinabilidad & Indeterminabilidad \\
\hline Receptividad & Espontaneidad \\
\hline Contenido procedimental no declarativo & Contenido declarativo \\
\hline
\end{tabular}

\section{Presentacionalidad frente a Representacionalidad}

Después del breve preámbulo, relativo al desarrollo cognitivo, paso a analizar el carácter presentacional de las categorías perceptivas, frente al carácter representacional de los conceptos. En La arquitectura cognitiva de la percepción el lector puede encontrar un desarrollo mucho más completo y pormenorizado de cómo las experiencias perceptivas de los seres humanos están constituidas por dos tipos de contenidos informativos, el sensorial y el categorial, y del modo o manera en la que el contenido categorial se configura en el sensorial. Pero en lo que ahora deseo centrarme es en el primero de los rasgos o propiedad que permite distinguir a las categorías perceptivas de los conceptos, el carácter presentacional de las categorías frente al representacional de los conceptos.

Cuando identificamos perceptivamente una entidad, propiedad o relación del mundo exterior, ya sea a través de la vista, el oído o cualquier otro de los sentidos, los contenidos sensorial y categorial de nuestra experiencia perceptiva tienen carácter presentacional. Lo que experimentamos 
perceptivamente o aquello de lo que tomamos conciencia en los procesos de percepción, supongamos que se trata de un perro, es del perro mismo que se encuentra ahí fuera frente a nosotros, con su color, su forma y su modo específico de estar ahí presente, sin que ningún intermediario se interponga entre nosotros y el animal. Nuestro acceso perceptivo al perro es directo, lo que estamos viendo, oyendo o tocando es directamente el perro, no una representación suya. Bien entendido, que esa experiencia directa lo es del perro, tal como éste está siendo identificado en el proceso de percepción. Y lo que se acaba de decir en relación con la percepción de un perro es igualmente aplicable a la percepción de cualquier otra entidad, propiedad o relación.

En el preciso momento en el que estoy viendo o tocando el teclado de mi ordenador, lo que veo y toco es el teclado del ordenador. Mi experiencia perceptiva lo es de estar viendo y tocando directamente el teclado del ordenador y en modo alguno una representación suya. Evidentemente, el contenido sensorial y categorial de mi experiencia perceptiva del teclado del ordenador es el resultado de un largo proceso en el que han intervenido la estimulación procedente del mundo exterior y el procesamiento que ha hecho de esa estimulación mi sistema perceptor, pero es del mundo así procesado, en este caso, del teclado del ordenador, del que tiene sentido decir que es real, que se encuentra ahí fuera frente a nosotros y que nuestra percepción de él es directa. Contraponer el mundo experimentado a un supuesto mundo "en sí”, del que el mundo perceptivamente experimentado sería una representación, es un planteamiento que carece de todo sentido. Es del mundo experimentado del que cabe decir con sentido que su existencia es independiente de nuestra experiencia de él, que sus propiedades le pertenecen, al margen de que yo o cualquier otro lo percibamos o dejemos de percibirlo. Pero lo que con esas expresiones se está realmente diciendo es que siempre que ese mundo sea objeto de percepción se manifestará de ese mismo modo a los sujetos que lo perciben. Atribuir propiedades a un supuesto mundo "en sí", del que nada podremos llegar a saber, porque no forma ni llegará a formar jamás parte de nuestra experiencia perceptiva u observacional, es un supuesto que carece de todo sentido, que no resuelve ningún problema ontológico ni epistemológico y que genera montones de ellos.

Por otra parte, tratar como representacionales a los contenidos sensorial y categorial de nuestras experiencias perceptivas implica no sólo la existencia de dos cosas, la representación y lo representado, sino también la posibilidad de acceder a ambas y sólo una de ellas está presente a nuestra con- 
ciencia en los procesos de percepción, el mundo, tal como éste está siendo experimentado en dichos procesos. Contraponer ese mundo experimentado a un supuesto mundo "en sí", para sostener que el mundo experimentado es una representación de ese mundo "en sí", genera, como se acaba de indicar, un montón de problemas. Y uno de ellos tiene que ver, precisamente, con el supuesto carácter representacional de los contenidos categorial y sensorial de nuestras experiencias perceptivas. Porque en dicho marco, como vamos a ver a continuación, la propia noción de representación carece de sentido.

Para poder afirmar de algo que es una representación de otra cosa necesitamos, como venía diciendo, no sólo poder disponer de esas dos cosas, la representación y lo representado, sino también poder acceder a ambas. De un plano de una ciudad puedo decir que es una representación de esa ciudad y no de otra cosa distinta de ella, porque tengo acceso al plano y a la ciudad y eso me permite establecer algún tipo de correspondencia entre el plano y la ciudad, entre la representación y lo representado. Si a uno cualquiera de nosotros nos presentan un plano de una ciudad y nos preguntan de qué ciudad ese plano es una representación, en el supuesto de que desconozcamos la ciudad de la que el plano supuestamente es una representación, nada podremos decir en relación con el supuesto carácter representacional del plano. ¿Representa el plano a esa ciudad o a otra distinta? ¿Es ese plano una correcta representación de la ciudad en cuestión? ¿Qué elementos de la ciudad no figuran en el plano? O, a la inversa, ¿qué elementos del plano están de más, porque no se corresponden con ninguna de las cosas existentes en la ciudad? Todas estas preguntas y otras muchas que podríamos hacernos en relación con el carácter representacional del plano, sólo podrán ser contestadas por alguien que tenga acceso al plano y a la ciudad supuestamente representada, pero no por alguien que desconozca la ciudad en cuestión. Y en este caso, el plano aun nos dice algo, porque se parece a los planos de otras ciudades que sí conocemos. Pero imaginemos, en lugar del plano de una ciudad, una figura, un gráfico, de algo que no hemos visto jamás y que no se parece en nada a ninguna de las cosas por nosotros conocidas. ¿Es eso una representación? ¿Qué motivos tenemos para considerar a esa figura o a ese gráfico como una representación? Pues esa y no otra es la situación en la que se encuentran todos aquellos que consideran a los contenidos de nuestras experiencias perceptivas como representacionales de un supuesto mundo "en sí”, al que nunca han accedido ni van a poder acceder jamás.

Como venía diciendo, para poder hablar de representación necesitamos no sólo la existencia de dos cosas, la representación y lo representado, sino también la posibilidad de acceder a ambas para, en virtud de ese acceso, 
poder decidir si una es o no es una representación de la otra. El hecho de que los contenidos de nuestras experiencias perceptivas sean el resultado del procesamiento que la arquitectura de nuestro sistema perceptivo realiza de los estímulos proximales no nos autoriza a considerar a esos contenidos como representacionales. En la percepción, al igual que en la observación científica, el mundo se nos presenta y es de esos contenidos presentacionales de los que, como luego veremos, nos hacemos representaciones.

La correspondencia entre la representación y lo representado no tiene por qué ser exclusivamente figurativa, como acontece en el caso de un plano, del mapa de un territorio, de una maqueta o de una fotografía. Mediante una fórmula física puedo representar la trayectoria de un proyectil y mediante una fórmula química la estructura de una molécula y en ninguno de los dos casos hay parecido físico entre la representación y lo representado, pero en ambos casos se puede establecer esa relación de correspondencia porque tenemos acceso a los dos elementos de la representación. Y sólo porque tenemos acceso a los dos elementos de la representación podemos afirmar que el plano de una ciudad, el mapa de un territorio, una maqueta, una fotografía, la fórmula física o la fórmula química son una buena o una mala representación de aquello a lo que representan, pero en el caso de la percepción esto no es posible, nuestro acceso lo es tan sólo al mundo experimentado y jamás a un supuesto mundo "en sí” del que el mundo experimentado sería una representación. En definitiva, que carece de todo sentido considerar a los contenidos sensoriales y categoriales de la percepción como representacionales, cuando además en modo alguno son experimentados como tales. En la percepción, digámoslo una vez más, el mundo se nos presenta, nuestro acceso a él es directo. Y es del mundo así experimentado en los procesos de percepción del que nos hacemos representaciones, las representaciones más básicas por su proximidad a la experiencia.

En el preciso momento en el que estamos percibiendo algo, no importa el tipo de cosa que sea ese algo, no existe un supuesto contenido de conciencia distinto de lo percibido. El contenido sensorial y categorial de mi experiencia perceptiva lo es de la entidad, propiedad o relación percibidas y no de algo distinto de ellas. Si tratásemos de llevar a cabo una descripción del contenido de nuestras experiencias perceptivas en el preciso momento en el que estas experiencias están teniendo lugar, esa descripción lo sería, en realidad, de aquello mismo que estamos percibiendo y no de algo distinto de eso. Lo percibido, el estado de cosas en el mundo, ese es el contenido de nuestras experiencias perceptivas. 
En los procesos de percepción el mundo se nos presenta, nuestro acceso a él es directo, bien entendido, digámoslo una vez más, que ese acceso directo lo es al mundo procesado. Pero es del mundo procesado, del que tomamos conciencia en los procesos de percepción, del que tiene sentido decir que se nos presenta, que nuestro acceso a él es directo, y se nos presenta como estando ahí fuera frente a nosotros, con una existencia y unas propiedades que le pertenecen y que como tales son experimentadas en los procesos de percepción. Pero si cabe hablar de esa existencia y esas propiedades del mundo es siempre en relación con un ente cognitivo que las experimenta o puede llegar a experimentarlas como tales. Como afirma expresamente Merleau-Ponty en Phénoménologie de la perception, "La chose ne peut jamais être séparée de quelqu'un qui la perçoive, elle ne peut jamais être effectivement en soi parce que ses articulations son celles mêmes de notre existence et qu'elle se pose au bout d'un regard ou au terme d'une exploration sensorielle qui l'investit d'humanité. ... Si l'on ne s'en est pas aperçu plus tôt, c'est parce que la prise de conscience du monde perçu était rendue difficile par les préjugés de la pensé objective. Elle a pour fonction constante de réduire tous les phénomènes qui attestent l' unión du sujet et du monde et de leur substituer l'idée claire de l'objet comme en soi et du sujet comme pure conscience" (Merleau-Ponty (1945): Phénoménologie de la perception, Gallimard, p. 370).

Lo que sea el mundo, independientemente de cómo es o puede llegar a ser experimentado por los entes cognitivos, es una pregunta sin respuesta posible. De ahí el sin sentido de considerar a los contenidos de nuestras experiencias perceptivas como representacionales, cuando, además, en modo alguno son experimentados como tales. Si, a pesar de todo, como dice Merleau-Ponty, presas del pensamiento objetivo, nos empecinamos en seguir manteniendo que los contenidos categoriales y sensoriales de nuestras experiencias perceptivas son representacionales, lo que en realidad estaremos haciendo es un mal uso del término representación, porque serán representacionales de algo a lo que nunca hemos accedido ni vamos a poder acceder y, en consecuencia, poco importa el contenido que adscribamos a esas representaciones puesto que nunca podremos saber si ese contenido se corresponde o no se corresponde con aquello de lo que supuestamente son representaciones. Lo que, evidentemente, carece de todo sentido. Como ya se ha indicado anteriormente, hablar de representación implica no sólo la existencia de dos cosas, la representación y lo representado, sino también la posibilidad de acceder a ambas, ya que sólo así cobra sentido la noción de representación, puesto que sólo así puede llegar a ser establecida la relación 
de correspondencia entre la representación y aquello de lo que la representación es representación.

A diferencia de lo que acontece con el contenido categorial de nuestras experiencias perceptivas, su representación conceptual en la palabra sí que es representacional. Una cosa es identificar perceptivamente a un perro, un gato, un árbol o cualquier otra entidad, propiedad o relación y otra muy distinta la representación que nos hacemos de esos distintos tipos o categorías de cosas mediante conceptos. En la percepción el mundo se nos presenta, nuestro acceso a él es directo. A través de los conceptos nos lo representamos. Con la particularidad de que de los dos tipos de contenidos presentes en los actos de percepción, el sensorial y el categorial, mediante los conceptos solamente se le da expresión al contenido categorial, lo que marca una profunda diferencia entre categorías perceptivas y conceptos. Esa diferencia, como ya hemos ido viendo en un apartado anterior, está ligada a la diversidad del soporte material en la que toman cuerpo, la información sensorial en el caso de las categorías perceptivas y la palabra, oral o escrita, en el de los conceptos.

Así como en nuestra experiencia del contenido categorial de la percepción sólo una cosa estaba presente a nuestra conciencia, en el uso representacional de los conceptos disponemos, por una parte, de ese contenido conceptual y, por la otra, de la clase de cosas en el mundo por él representadas, los contenidos categoriales de la percepción. Y, como es evidente, no sólo disponemos de esas dos cosas, sino que tenemos acceso a ambas y en consecuencia, podemos decidir acerca de su relación de correspondencia. Si afirmo que hay un perro de color negro en el jardín de mi casa y, al salir al jardín, constato que, efectivamente, hay un perro en el jardín pero que el perro no es de color negro sino gris, puedo concluir que la representación mental que me había hecho del perro en el jardín sólo en parte se corresponde con los contenidos categoriales de esa percepción. El concepto de perro representa correctamente a la categoría perceptiva de perro, pero el concepto de color negro no se corresponde con el de la categoría perceptiva del color gris con el que el perro está siendo experimentado en el proceso de percepción. Como se pone de manifiesto en el ejemplo, la relación de correspondencia es posible porque no se establece entre una representación mental y un supuesto mundo "en sí" del que pretenden hablar los realistas externalistas, sino entre dos experiencias del sujeto, una a nivel de la representación mental y la otra a nivel perceptivo. Lo que sirve de referente a nuestros conceptos más básicos y próximos a la experiencia no es el supuesto mundo "en sí" del realismo externalista, sino el mundo categorial 
del que tomamos conciencia en los procesos de percepción u observación científica.

\section{Horizontalidad frente a no horizontalidad}

Como hemos estado viendo en el punto anterior, los contenidos categorial y sensorial de nuestras experiencias perceptivas tienen carácter presentacional y de esos dos contenidos sólo uno de ellos, el categorial, es objeto de representación simbólica, en forma de conceptos, a través del lenguaje. Pero el hecho de que a nivel perceptivo los contenidos categoriales de la percepción se constituyan en la información sensorial, y a nivel conceptual tomen cuerpo en la palabra, marca diferencias importantes entre categorías perceptivas y conceptos. Una de esas diferencias, ya vista, es el carácter presentacional de las categorías perceptivas frente al representacional de los conceptos. Una segunda diferencia, que vamos a ver a continuación, es el carácter de horizontalidad de los contenidos categoriales de la percepción frente a la no horizontalidad de los conceptos.

A nivel perceptivo la información categorial se configura siempre sobre una de las múltiples dimensiones sensoriales de aquello que está siendo percibido, la dimensión sensorial que en cada acto de percepción se nos está haciendo presente, por más que el resto de dimensiones sensoriales de lo percibido estén implícitamente presentes como potencialmente perceptibles. Es decir, a nivel perceptivo, el contenido categorial se nos manifiesta siempre en el marco de una determinada perspectiva. Un perro, un gato o un pájaro pueden ser identificados como tales desde múltiples perspectivas distintas y en cada una de esas perspectivas la misma información categorial se configura en informaciones sensoriales distintas, la relativa a cada perspectiva. Un perro, pongamos por caso, puedo identificarlo como ese tipo de animal viéndolo de costado, de frente o de espalda, e incluso viendo solamente alguna de las partes de su cuerpo u oyéndolo ladrar y, en cada una de esas percepciones, la información sensorial sobre la que se asienta la identificación categorial del animal como un perro será distinta, pero esto no afecta al contenido categorial de la percepción, siempre claro está, que a través de esa información sensorial el animal sea identificado como un perro. A lo que sí afecta es al modo de dársenos ese contenido categorial en los procesos de percepción que, al configurarse sobre la información sensorial, lo hará siempre en cada acto de percepción vinculada a la información sensorial relativa a la posición del sujeto en relación con la entidad, propiedad o relación percibidas. En definitiva, que en los procesos de percepción la identificación categorial de una entidad como tal entidad se nos hace 
siempre presente vinculada a una determinada información sensorial que, a su vez, está determinada por la posición relativa del sujeto con relación a la entidad, propiedad o relación percibidas. Por el contrario, a nivel simbólico la representación conceptual de los contenidos categoriales de la percepción no está sujeta a perspectivismo alguno. Los conceptos de "perro", "gato" o "pájaro" representan a sus respectivas categorías o tipos de cosas en el mundo, desligados de la particular información sensorial en la que, en cada caso, se constituyen a nivel perceptivo y, por lo tanto, desligados de cualquier tipo de perspectiva. Cuando utilizo la palabra "perro" para referirme a la clase de los perros, mi representación simbólica del concepto de perro no está afectada de perspectivismo alguno. Refiere, sin más, a la clase de los perros como tal clase. El perspectivismo reaparece a nivel de la representación conceptual, si a esa representación conceptual va asociada una imagen, pero las imágenes, que en algunos casos pueden ir asociadas a los conceptos, no son un constitutivo esencial de los contenidos conceptuales. Los conceptos cumplen con su función representacional a nivel simbólico, independientemente de las imágenes que en algunas circunstancias puedan asociárseles y que, en cualquier caso, pertenecen a la experiencia privada de cada sujeto y no son objeto de comunicación lingüística. Los conceptos más próximos a nuestras experiencias perceptivas, como pueden serlo los conceptos de perro, gato, pájaro, casa, árbol, silla, mesa, etc., pueden, en su uso habitual, llevar asociada algún tipo de imagen, posiblemente la imagen más o menos borrosa del tipo de entidades que han servido de ejemplares a cada sujeto en la adquisición de las categorías perceptivas correspondientes a esos conceptos. Pero esas imágenes pertenecen a la experiencia privada de cada uno de nosotros y, como ya se ha indicado anteriormente, no son objeto de comunicación lingüística y tampoco son un constitutivo esencial del contenido conceptual. A través del lenguaje se da expresión al contenido conceptual, no a las imágenes que unos sujetos u otros puedan asociar a esos contenidos conceptuales y los contenidos conceptuales como tales no están sujetos a perspectivismo alguno, a diferencia de lo que acontece con los contenidos categoriales de la percepción, que se nos hacen siempre presentes vinculados a una determinada perspectiva, la proporcionada por la información sensorial sobre la que, en cada caso, se constituye la categoría perceptiva correspondiente.

\section{Determinabilidad frente a indeterminabilidad}

Una diferencia más entre el contenido categorial de la percepción y su representación conceptual se deriva, una vez más, del tipo de material sen- 
sible en el que, en cada caso, toman cuerpo esos contenidos categoriales. A nivel de la percepción el contenido categorial se configura siempre en una de las dimensiones sensoriales de lo percibido, mientras que a nivel conceptual es la palabra la que sirve de cuerpo al pensamiento. De ese hecho se deriva esa doble dimensión de generalidad y singularidad con la que las entidades percibidas se nos manifiestan en los procesos de percepción, frente a la sola dimensión de generalidad con la que son representadas a nivel conceptual. Cuando identifico perceptivamente a un animal como un perro, además de identificarlo como tal, y esa es una dimensión abstracta y general, lo identifico también como un ejemplar singular de esa clase de animales, lo que viene determinado por la propia singularidad de la información sensorial en la que se configura la categoría. Por el contrario, a nivel de la representación simbólica a través de la palabra, el concepto de perro refiere de una manera abstracta a la clase de los perros en general, sin referencia alguna a ningún ejemplar en particular. Evidentemente, a través del lenguaje también podemos tratar de referirnos a entidades singulares, en nuestro ejemplo, a un perro en concreto, haciendo uso de expresiones como "mi perro" o "tu perro" o bien mediante el uso de un nombre propio, el nombre que convencionalmente se le haya asignado al perro, pero en estos casos, la singularidad como tal no es dada, sólo sugerida. El sujeto que no haya tenido la experiencia perceptiva del animal en cuestión, sigue sin conocer la singularidad de dicho animal. La singularidad de las entidades del mundo se nos da exclusivamente a través de sus dimensiones sensoriales y éstas no son objeto de expresión lingüística. Puedo comunicarle a alguien que "mi perro es negro", de "tal o cual tipo de raza", pero ese tipo de información sigue siendo conceptual. Lo único que he hecho mediante esas expresiones es, justamente, dar expresión a las categorías de negro y raza, referidas a mi perro. La singularidad identificativa la proporciona única y exclusivamente la información sensorial y ésta no es susceptible de ser expresada en conceptos. Por muy detallada que sea la descripción conceptual de una entidad, propiedad o relación siempre cabe la posibilidad de imaginarse dos o más entidades, propiedades o relaciones que cumplan la descripción y que, sin embargo, sean distintas entre sí. Supongamos que alguien nos dice que tiene un hermano y nos proporciona una larga lista de sus características físicas. La sola descripción conceptual nunca será suficiente para identificar perceptivamente a esa persona. De los dos contenidos de la percepción, el sensorial y el categorial, el lenguaje en el que los conceptos toman cuerpo, sólo da expresión al contenido categorial. La información sensorial pertenece a la experiencia privada de cada sujeto y no es susceptible de ser comunicada 
mediante conceptos. Lo que marca una diferencia más entre los contenidos categoriales de la percepción y su representación conceptual.

\section{Receptividad frente a espontaneidad}

En relación con el material sensible en el que se configuran los contenidos categoriales de la percepción, por una parte, y su representación conceptual en la palabra, por la otra, nos encontramos con una diferencia más entre ambos contenidos.

A nivel de la percepción los contenidos categoriales se configuran en la información sensorial y los vínculos entre la información sensorial y los contenidos categoriales en ellos configurados son naturales. Son los propios contenidos de la información sensorial los que dan cuerpo a la información categorial y hacen que identifiquemos esa información sensorial como la información sensorial de tal o cual tipo de entidad. Y eso es así porque es justamente la información sensorial relativa a cada categoría o tipo de entidades en el mundo, la que posibilita y da cuerpo a la categoría correspondiente.

Como ya se ha señalado en páginas anteriores, a nivel perceptivo no es posible desligar la información categorial de la información sensorial en la que se configura, están como envueltas la una en la otra y, a su vez, esa información sensorial, en su conjunto, será la información sensorial del tipo o categoría de entidad, propiedad o relación en ella configurada. Si un sujeto, pongamos por caso, ha aprendido a distinguir a los perros de los gatos, cuando ve un perro, en la información sensorial del perro verá necesariamente a un perro y no a un gato y lo verá con el color, la forma y el tamaño concretos que tiene ese animal. No tenemos la libertad de poder percibir configurada en la información sensorial relativa a un determinado tipo de entidad, cualquier otro tipo de entidades que no sean las específicas de esa información sensorial. En el caso de la percepción el contenido categorial configurado en la información sensorial se nos impone. Como diría John McDowell (McDowell, J., 1994) hay receptividad y no espontaneidad.

No tenemos la posibilidad de ver o percibir en una determinada información sensorial aquello que se nos antoje sino el tipo de entidad propiedad o relación configuradas por esa información sensorial. Bien entendido que una misma información sensorial, en momentos distintos y dependiendo, en cada caso, de la intencionalidad del sujeto perceptor, puede dar cuerpo a informaciones categoriales distintas. Pero se trata siempre de informaciones categoriales determinadas en y por la propia información sensorial y no por nuestra voluntad. De nuestra voluntad sólo depende la dimensión catego- 
rial a la que en cada caso decidimos prestar atención. De una mesa podemos tomar en consideración en un momento dado su ser mesa y en otros momentos distintos su color, su forma, su tamaño, el material del que está hecha, el lugar en el que se encuentra, etc. etc. En cada uno de esos actos de percepción la misma mesa ha sido objeto de identificaciones categoriales distintas, pero todas ellas vienen determinadas por la propia información sensorial y no por nuestra voluntad. Nuestra voluntad lo único que puede determinar es la dimensión de la mesa que en cada caso va a ser tomada en consideración pero no el contenido categorial y sensorial de esa dimensión. Por el contrario, cuando algunas de esas informaciones categoriales son objeto de representación conceptual en la palabra, pierden su vinculación con la información sensorial en la que se habían constituido a nivel perceptivo y adquieren el carácter abstracto y de espontaneidad propio de los contenidos conceptuales.

A nivel conceptual puedo referirme a las distintas entidades del mundo en general, o a una cualquiera de sus dimensiones, pero la entidad o dimensión mentada, el contenido conceptual de mi mención, aunque se trate de una dimensión sensorial, como lo pueden ser el color, la forma o la posición, lo será de la categoría correspondiente a esa dimensión sensorial, pero no del contenido sensorial particular del que sí puedo tomar conciencia en los actos de percepción. De los contenidos sensoriales no categorizados de la percepción podemos disponer atencional y conductualmente en el momento en el que están siendo percibidos (Vázquez, J. 2013, 2014), pero no conceptualmente. No tenemos memoria perceptiva de ellos. Su ser va vinculado a la presencia. De dos matices de color, muy próximos el uno al otro, podemos distinguirlos cuando los estamos viendo y comprobar que, efectivamente, se trata de dos matices distintos del mismo color, pero si en un momento posterior nos presentan uno de ellos para que indiquemos de cuál de los dos matices se trata, lo más probable es que no lo sepamos, porque no han sido objeto de categorización y, por lo tanto, no tenemos una representación conceptual de esos contenidos sensoriales. Algo muy distinto es lo que va a suceder si lo que se trata de recordar son colores o matices de color categorizados, para los que sí disponemos de representación conceptual como, por ejemplo, para los colores azul y verde o para los matices de color azul marino y azul zafiro, pero lo que en realidad se recuerda no es el matiz concreto y singular del color percibido sino la categoría en él configurada y que es o puede llegar a ser objeto de representación conceptual en el lenguaje.

Como ya se ha indicado tantas veces, de los dos contenidos presentes en todo acto de percepción, el sensorial y el categorial, sólo el contenido ca- 
tegorial es objeto de representación conceptual en la palabra y actúa como referente de los enunciados de percepción. Con la particularidad de que a nivel perceptivo, el contenido categorial, al configurarse en la información sensorial, adquiere una doble dimensión, la de generalidad, propia de la categoría y la de singularidad, específica de los contenidos sensoriales en los que se constituye. Al mismo tiempo que identifico a un animal como un perro, como un miembro de la categoría perro, lo identifico también como un perro singular y único, distinto del resto de los miembros de la especie. Y esa dimensión de singularidad nos es dada por la información sensorial en la que, en cada caso concreto, se configura la información categorial.

Así como la vinculación del contenido categorial de la percepción con el contenido sensorial en el que se configura es natural, la vinculación del contenido categorial con la palabra en la que toma cuerpo a nivel conceptual es puramente convencional, de ahí el carácter simbólico, representacional y de espontaneidad del que están imbuidos los contenidos conceptuales.

\section{Conocimiento no declarativo frente a conocimiento declarativo}

Como ya se ha indicado tantas veces, las categorías perceptivas están atadas a la información sensorial en la que se configuran a nivel perceptivo, su ser no es algo distinto del modo en el que las cosas tienen de ser cosas en el mundo para los entes cognitivos. Porque identificamos perceptivamente a un animal como un perro, nuestra conducta con relación al perro estará guiada por los conocimientos vinculados a la categoría de los perros, si la identificación lo fuese del animal como un lobo, nuestra conducta sería totalmente distinta. En la percepción, además de identificar a los distintos entes del mundo como singulares y únicos son identificados también como perteneciendo a un determinado tipo o categoría de entidades. La identificación categorial de los ítems en el mundo no está determinada porque proyectemos o dejemos de proyectar sobre ellos las estructuras léxicas de las que hacemos uso a nivel conceptual, sino al contrario, es la identificación de ese animal como un perro o un lobo la que puede traer a nuestra mente la etiqueta léxica correspondiente. Las etiquetas léxicas y con ellas los conceptos, no son los que dotan de contenido a las categorías perceptivas, se limitan simplemente a proporcionarles expresión lingüística y, en consecuencia, a transformar los contenidos categoriales de la percepción en conocimientos declarativos, pero son los contenidos categoriales de la percepción los que actúan como determinantes. Si el animal es identificado como un perro, estoy forzado a etiquetarlo con la palabra "perro", con el término que convencionalmente es utilizado para designar a ese tipo de animales. Etiquetarlo 
con la palabra "lobo", tratando de proyectar el concepto de lobo sobre lo que perceptivamente ha sido identificado como un perro, no es posible y no es posible hacerlo porque lo impide la información categorial configurada en esa información sensorial. Los contenidos categoriales de la percepción, una vez constituidos, su configuración en la información sensorial es nítida y determinante. Y el que esos contenidos nos parezcan más precisos cuando toman cuerpo en la palabra y adquieren el nivel conceptual, es debido única y exclusivamente a la diversidad del material sensible en el que toman cuerpo, los contenidos sensoriales de la percepción en un caso y la expresión léxica en el otro. Con la particularidad de que a nivel de la expresión léxica es la neutralidad del signo, su ser convencional, la que produce esa supuesta impresión de claridad y precisión atribuida a los conceptos. Pero bajo esa impresión de claridad y precisión subyace, en la inmensa mayoría de los casos, un vasto pluralismo semántico (Barsalou, 1987; Thelen \& Smith, 1994). El pluralismo semántico heredado de las distintas situaciones en las que los contenidos categoriales de la percepción han sido aprehendidos y de los diversos contextos en los que, a nivel lingüístico, los conceptos correspondientes son o pueden ser utilizados. Como se acaba de indicar, son las palabras, en las que los conceptos toman cuerpo, las que producen esa impresión de unidad, claridad y precisión, pero, en realidad, las palabras son como perchas de las que cuelgan una pluralidad, no del todo bien definida en la mayoría de los casos, de contenidos semánticos distribuidos en redes neuronales que se extienden por las distintas áreas de la corteza cerebral, donde han sido procesados y almacenados. Y, a nivel conceptual, se activarán en cada caso algunos de esos contenidos, los relativos al contexto en el que el concepto es utilizado. Es la representación simbólica, vinculada al lenguaje, la que permite o, mejor dicho, posibilita el carácter composicional del conocimiento conceptual, manipulando los conceptos como si se tratara de unidades bien definidas y es su distribución en redes neuronales las que explicarían esa variabilidad semántica que las investigaciones empíricas sobre los conceptos y sus contenidos ponen de manifiesto ${ }^{3}$.

${ }^{3}$ Given that many real-life categories (e.g., dogs, cats, or cups) are acquired by perceptual means and later undergo lexicalization, there are reasons to believe that these categories combine perceptual representation with a more abstract lexicalized representation. These abstract lexicalized representations are critically important for the ability to reason and form arguments that could be all but impossible to form by strictly perceptual means" (p. 1249). Sloutsky, Vladimir M. (2010): "From Perceptual Categories to Concepts: What Develops?", Cognitive Science, 34 (2010), pp. 1244-1286. 
El contenido conceptual vinculado a la palabra “pez”, pongamos por caso, lo experimentamos como singular y único, y podemos hacer un uso de él en un número ilimitado de composiciones lingüísticas distintas, sin embargo su contenido semántico variará significativamente de unos contextos a otros (Yeh, W., Barsalou, L.W., 2006). El contenido semántico asociado a dicho término por un grupo de pescadores y en un contexto de pesca es significativamente distinto del que asociarían a ese mismo término un grupo de chefs en el contexto de su preparación en la cocina de un restaurante o un grupo de comensales en el comedor de ese mismo restaurante. En sus Investigaciones filosóficas (Parágr. 66-71), Wittgenstein analiza el concepto de "juego" con el propósito de poner al descubierto esa falta de unidad vinculada a los conceptos, para mostrar que es tan sólo un ligero "aire de familia" lo que subyace a los distintos contextos en los que el término "juego" y, por lo tanto, el concepto correspondiente, puede ser utilizado. Pero, como venía diciendo, es la neutralidad de las expresiones léxicas en las que los contenidos conceptuales toman cuerpo a nivel del lenguaje, la que proporciona a los conceptos ese aparente halo de unidad, cuando, a poco que se los analice, lo que más bien se constata es que la inmensa mayoría de los conceptos presentan unos límites poco definidos. De ahí la enorme dificultad con la que nos encontramos cuando tratamos de proporcionar la definición precisa de un concepto, siempre, claro está, que no se trate de conceptos formales y algunos, relativamente pocos, conceptos científicos y también de la vida ordinaria, para los que sí podemos proporcionar una definición precisa.

A diferencia de lo que acontece con los contenidos conceptuales que, al objetivarse en la palabra, adquieren, entre otros, el rango de conocimiento explícito y declarativo, los contenidos categoriales de la percepción están ahí ante nosotros, configurados en la información sensorial, sirviendo de guía a nuestra interacción con el medio. No se trata de ningún tipo de conocimiento implícito o puramente procedimental del que no seamos conscientes, pero es a través de la expresión léxica como los contenidos categoriales de la percepción adquieren el rango de conocimiento simbólico y declarativo, lo que es propio del conocimiento conceptual. A nivel de la percepción el contenido categorial es claro y preciso, no se trata de ningún tipo de conocimiento implícito, inconsciente o puramente procedimental, lo único que acontece es que va indisolublemente unido a la información sensorial en la que se configura y es su presentacionalidad, el acceso directo a él, lo único que importa en la guía de nuestra interacción con el medio. Tomar conciencia explícita del contenido categorial de nuestras experien- 
cias perceptivas, cuando de lo único que se trata es de que sirva de guía a la acción en nuestra interacción con el medio y con los otros sujetos, no sólo constituiría un gasto inútil de energía, sino que incluso podría actuar como una especie de distractor que ralentizaría la acción. Sólo cuando deseamos objetivar el contenido categorial de nuestras experiencias perceptivas, en el sentido de tomar una conciencia explícita de él, acudimos a la expresión léxica, desligándolo, de ese modo, de la información sensorial en la que se configura a nivel perceptivo. Pero es la información categorial la que demanda la expresión léxica correspondiente y no la expresión léxica conceptual la que fija el contenido categorial. De ahí que en los procesos de verificación o contrastación empírica de los enunciados de percepción, sea la información categorial la que, en última instancia, tiene la última palabra, pone el sello de verdadero o falso a nuestras expectativas cognitivas. Pude haber bajado al jardín con la expectativa de que el perro que había visto desde la ventana era de color negro, pero si al llegar al jardín constato que el perro es de color gris y no de color negro, que es la categoría de gris la realmente configurada en la información sensorial de mi percepción del perro, diré que el perro es gris, que la identificación visual del color del perro que había hecho desde la ventana no era verídica ${ }^{4}$, por lo tanto, falsa mi expectativa de que el perro era negro.

Una vez que los contenidos categoriales de la percepción toman cuerpo en la palabra, se independizan de la información sensorial en la que se constituyen a nivel perceptivo y en su nuevo estatus de conceptos, adquieren, por decirlo de una manera gráfica, vida propia. De tal modo que a partir de los pensamientos ya constituidos podemos acceder a la constitución de nuevos pensamientos y esos nuevos contenidos conceptuales pueden, a su vez, influir en nuestras experiencias perceptivas u observacionales de múltiples maneras distintas: haciendo, por ejemplo que, en función de nuestra relación con el medio, prestemos atención a nuevas dimensiones de la realidad, posibilitando el establecimiento de nuevas categorías perceptivas, el enriquecimiento de las ya existentes o su modificación, etc. etc. Pero en la confrontación de los contenidos conceptuales con los contenidos categoriales de la percepción son los contenidos categoriales los que, en última instancia, tienen la última palabra. Quien no tenga las categorías perceptivas

${ }^{4}$ En el Capítulo III de Mente y mundo. Aproximación neurológica se proporciona un criterio con el que distinguir las experiencias perceptivas verídicas de las no verídicas. En síntesis, lo que dicho criterio viene a decir es que la experiencia perceptiva de un ítem es verídica si es intersubjetivamente compatible con el resto de experiencias de ese mismo ítem y es no verídica en el caso contrario. 
de gorrión o petirrojo no podrá ver en un pájaro un gorrión o un petirrojo, pero lo que sí podrá ocurrir es que una aproximación conceptual a las nociones de gorrión y petirrojo contribuya positivamente al establecimiento de las categorías perceptivas correspondientes, pero, a su vez, esos dos tipos de categorías distintas no podrían ser establecidas si no hubiera una base empírica sobre la que fundamentar la distinción entre la categoría de los gorriones por una parte y la de los petirrojos por la otra.

Esos son, en síntesis, los rasgos más sobresalientes que permiten distinguir a las categorías perceptivas de los conceptos que, como acabamos de ver, se fundamentan en la diversidad del material sensible en el que se configuran las categorías perceptivas, por una parte, y toman cuerpo los conceptos, por la otra.

\section{Conclusiones}

En este trabajo se ha partido de las evidencias proporcionadas en estos últimos años por las investigaciones empíricas acerca de la cognición humana, acerca del modo en que las personas adquieren conocimientos en el curso del desarrollo y aprendizaje. Según estos estudios, los humanos, a través de los procesos de percepción y desde los primeros meses de vida, tendemos, de una manera implícita, no consciente y automática, a agrupar la información sensorial, derivada del procesamiento de los estímulos, en clases significativas, mediante la búsqueda de rasgos compartidos, lo que es fundamental para la supervivencia, ya que nos permite tratar a los miembros de la misma categoría o clase de una manera similar. Este proceso implica una simplificación del medio, una reducción de la carga de la memoria, un modo de almacenar y recuperar información que va más allá del reconocimiento de los entes singulares. En definitiva, unos logros que se alcanzan mediante el procedimiento de taxonomizar el mundo.

Una vez que los sujetos ya disponen de un determinado sistema de categorización o taxonomización del medio, la percepción proporciona a esos sujetos dos tipos distintos de información, la sensorial o subcategorial y la categorial en ella configurada. A partir de esos datos, lo que me he propuesto en este trabajo y creo haber logrado, ha sido mostrar que rasgos o propiedades permiten distinguir de una manera clara y precisa la información categorial, configurada en la información sensorial, de los conceptos propiamente dichos y en qué momento del desarrollo cognitivo y bajo qué condiciones se produce el paso o transformación de las primeras categorías 
perceptivas adquiridas por el sujeto, en general las categorías perceptivas de nivel básico, en conceptos.

\section{Bibliografía}

Barsalou, L. W. (1987): “The instability of graded structure: Implications for the nature of concepts". In U. Neisser (Ed): Concepts and conceptual development (pp. 101-140), New York, Cambridge University Press.

Davidson, M. C., Amso, D., Anderson, L. C., \& Diamond, A. (2006). Development of cognitive control and executive functions from 4 to 13 years: Evidence from manipulations of memory, inhibition, and task switching. Neuropsychologia, 44, 2037-2078. https://doi.org/10.1016/j. neuropsychologia.2006.02.006

Goldstone, R. L., \& Kersten, A. (2003): “Concepts and Categorization” In A.F. Healy \& R. W. Proctor (eds.): Comprehensive handbook of psychology, Vol. 4: Experimental psychology, (pp. 599-621, New Jersey: Wiley. https://doi.org/10.1002/0471264385.wei0422

McDowell, J. (1994): Mind and World, Cambridge, MA, Harvard University Press (Vers, cast. McDowell, J. 2003: Mente y Mundo, Salamanca, Sígueme).

Mandler, J.M.(2004): The Foundations of Mind. Origins of Conceptual Thought, Oxford University Press. https://doi.org/10.1111/j.14677687.2004.00369.x

Markman, Ellen M. (1989): Categorization and Naming in Children: Problems of Induction; Cambridge, Massachusetts [etc.],MIT Press.

Merlau-Ponty, M. (1945): Phénoménologie de la perception, Paris, Gallimard.

Murphy, Gregory L. (2004): The big book of concepts. Cambridge, Massachussets, MIT Press.

Nelson, K. (1973). Structure and strategy in learning to talk. Monographs of the Society for Research in Child Development, 38(1-2), 1-137. https://doi.org/10.2307/1165788

Rosch, E., Mervis, C. B., Gray, W., Johson, D., and Boyes-Braem, P. (1976): "Basic objects in natural categories", Cognitive Psychology, 8, 382-439. https://doi.org/10.1016/0010-0285(76)90013-X

Sloutsky, Vladimir M. (2010): "From Perceptual Categories to Concepts: What Develops? Cognitive Science, 34 (2010), pp. 1244-1286. https://doi.org/10.1111/j.1551-6709.2010.01129.x 
Smith, J. D., Redford, J. S., \& Haas, S. M. (2008). Prototype abstraction by monkeys (Macaca mulatta). Journal of Experimental Psychology: General, 137, 390-401. https://doi.org/10.1037/0096-3445.137.2.390

Thagard, Paul and Ethan Toombs (2005): "Atoms, Categorization and Conceptual Change", en Handbook of Categorization in Cognitive Science Edited by: Henri Cohen and Claire Lefebvre, Oxford, Amsterdam, Boston ..., ELSEVIER.

https://doi.org/10.1016/B978-0-08-101107-2.00018-X

Thelen, E. \& Smith, L. B. (1994): A dynamic systems approach to the development of cognition and action, Cambridge, MA, MIT Press.

Vázquez, J. (2007): Mente y mundo. Aproximación Neurológica, Madrid, Akal.

Vázquez, J. (2013): La arquitectura cognitiva de la percepción, Servicio de Publicaciones de la Universidad de Santiago de Compostela, handle: http://hdl.handle.net/10347/8031

Vázquez, J. (2014): The Cognitive Architecture of Perception, Instituto de Filosofía, Universidade de Porto. (editado como eBook por el Servicio de Publicaciones de la USC. http://dx.doi.org/10.15304/op.2016.956

Wallace, M. T. (2004): "The development of multisensory processes”, Cognitive Processing, 5, pp. 69-83. https://doi.org/10.1007/s10339-004-0017-z

Wittgenstein, L. (1953): Philosophische Untersuchungen, Basil Blackwell Publisher, Oxford (Trad. Cast. de Alfonso García Suárez y Ulises Moulines, (1988).

Yeh, W., Barsalou, L.W., (2006): The situated nature of concepts. Am. J. Psychol. 119, 349-384. https://doi.org/10.2307/20445349 